\title{
Serum Cartilage Oligomeric Matrix Protein (COMP) estimation: a tool to assess efficacy of treatment in knee osteoarthritis
}

\begin{abstract}
Context: Osteoarthritis is a leading cause of disability in older adults. Various treatment options present, ranging from lifestyle modification to total knee replacement. What is the effect of on-going treatment over disease and at what stage the patient requires change of therapy is the questions which still need to be answered. Developing an investigatory modality to provide information about efficacy of on-going treatment is the need of the hour.
\end{abstract}

Aim: Aim of present study is to estimate and compare serum levels of Cartilage Oligomeric Matrix Protein (COMP) for assessing efficacy of treatment and disease prognosis in patients having knee osteoarthritis.

Settings and design: It is a prospective randomized control trial which was conducted in the Department of orthopedics, in a tertiary care teaching hospital in Northern India within a period of two year recruiting 100 cases.

Methods and materials: All the cases were asked to fill the WOMAC questionnaire and Kellgren Lawrence (KL) Grading was done for all. The serum level of COMP was estimated by ELISA. The value of serum COMP was compared with WOMAC score and KL grading scale. The cases were prescribed medications according to standard management guidelines of OARSI. Follow up was done after every four weeks to assess the efficacy of treatment and disease progression.

Results: The level of increase in Serum COMP corresponds to the severity of disease, and radiological staging. In almost all treatment groups Serum COMP level exhibited a downward trend which is gradually regressive with increasing time and continued therapy. In mild cases, the patients treated with Diacerin and lifestyle modification showed best results clinically and in lab values. In moderate cases, the patients treated with Diacerin, Glucosamine with MSM and lifestyle modification showed best results clinically and in lab values. In severe cases, patients treated with Diacerin, Glucosamine with MSM showed best results clinically and in lab values.

Conclusion: Serum COMP levels can be used as a prognostic and therapeutic indicator of knee osteoarthritis. The Serum COMP levels give a quantitative explanation about the effectiveness of ongoing treatment. In both mild and moderate knee osteoarthritis, combination of lifestyle modification with pharmacotherapy is superior over pharmacotherapy alone. In severe cases serum COMP values show least improvement, which indicates about limited control of pharmacological therapy in these patients.

Keywords: Osteoarthritis, COMP, ELISA, WOMAC
Volume I Issue 3 - 2014

\author{
Sudhir Singh,' Neha Tiwari Shahi, ${ }^{2}$ Utkarsh \\ Shahi,' Dharmendra Kumar' \\ 'Department of Orthopaedics, Era's Lucknow Medical College, \\ India \\ ${ }^{2}$ Department of Microbiology, Sanjay Gandhi Post Graduate \\ Institute, India
}

Correspondence: Sudhir Singh, Department of Orthopaedics, Era's Lucknow Medical College, Lucknow, India, Tel 918799544905, Email susi59@live.in

Received: October 26, 2014 | Published: November 09, 2014
Abbreviations: COMP, Cartilage Oligomeric Matrix Protein; WOMAC, Western Ontario and McMaster Universities Osteoarthritis Index; KL, Kellgren Lawrence; OARSI, Osteoarthritis Research Society International; OA, Osteoarthritis; RA, Rheumatoid arthritis; ELISA, Enzyme Linked ImmunoSorbate Assay

\section{Introduction}

Cartilage Oligomeric Matrix Protein (COMP) is one of the best studied markers of osteoarthritis. It is produced by chondrocytes as well as synovicytes and can serve as a marker for either cartilage degradation or synovium turnover or both. ${ }^{1}$ COMP has a role in regulation of fibril assembly and maintenance of the mature collagen network. The total amount of COMP in osteoarthritic cartilage is same as normal cartilage but with higher proportions of degraded fragments. These fragments diffuse in the joint fluid and thereby appear in circulation. The high COMP circulating levels indicate increased cartilage degradation, which occurs in osteoarthritis ${ }^{2,3}$ Darweesh et al. ${ }^{4}$ explained that COMP is one of the biochemical markers of connective tissue matrices that are released into the biological fluid during the process of tissue turnover. Thus, these markers may have a role to assess the disease severity progression and possibly efficacy of therapeutic interventions in RA and OA patients in times to come.

\section{Subjects and methods}

The study was cleared by the research cell and the ethical committee of the institution. Cases were recruited after proper history taking and thorough physical examination, taking into consideration, all inclusion criteria, whereas all the exclusion criteria were meticulously sought and ruled out. All those who were included in the study were explained about the study and included in the study after written consent. A total 
of 100 cases (50 males and 50 females) were recruited in the study. All the cases were asked to fill the WOMAC questionnaire to assess the presence and severity of disease and bilateral knee radiograph was done, to assess the severity of disease with the help of Kellgren Lawrence Scale. WOMAC scoring and estimation of sCOMP was also done at monthly intervals up-to the last follow up. The duration of follow up was 6 months in mild, 9 months in moderate and 1 year in severe cases. Present study is the second part of the study done earlier and results reported by us. Earlier we had reported the role of serum COMP levels in early diagnosis and severity of knee osteoarthritis. ${ }^{5}$

Inclusion criteria were guided by American College of Rheumatology Clinical Classification Criteria for Osteoarthritis of the knee. ${ }^{6}$ Inclusion criteria specified men and non-pregnant women of 40-85 years of age with primary OA of at least one knee with any three or more of the following:

i. Stiffness after a period of rest and joint stiffness in early morning

ii. Painful and restriction of joint movement

iii. Audible or palpable bony crepitus of joints during movement

iv. Synovitis around knee

v. Bony enlargement of joints

vi. No palpable warmth of synovium

Patients were excluded if they had

i. Secondary arthritis (inflammatory or metabolic arthritis)

ii. Corticosteroid use currently or within the previous 2 weeks

iii. On-going treatment with any category of drugs

iv. Sensitivity to any NSAID

v. Clinically active renal, hepatic or peptic ulcer disease

vi. History of alcohol or drug abuse and

vii. Other disabling conditions of knee

\section{Methodology}

Weight bearing antero-posterior knee radiographs were taken for all subjects. All subjects were made to rest for half an hour in seated position before blood samples were drawn to avoid the effect of activity on sCOMP levels. Samples were drawn in late mid-day (12 noon to $4 \mathrm{pm}$ ) to avoid diurnal variations. Five $\mathrm{ml}$ whole venous blood sample were drawn in syringe and collected in plain vial with aseptic technique. Samples were sent to Immunology laboratory in Table I Comparison of Serum comp Values before and after therapy in mild Cases
Department of Microbiology, for estimation of serum COMP levels by ELISA test (RD194080200 Human cartilage oligomeric matrix protein ELISA). Blood was centrifuged and serum was separated and stored in vials for long term use.

Severity assessment of the disease was done clinically and with WOMAC questionnaire and KL scale. The cases divided into mild, moderate and severe grades. The severity of osteoarthritis was graded on plain radiographs by K-L grading (0-IV). The KL scale 0 was graded as normal, KL Grade I and II as mild OA, with KL Grade III as moderate OA and KL Grade IV as severe OA. The cases were prescribed medications according to standard management algorithm on the guidelines of Osteoarthritis Research Society International (OARSI). ${ }^{7}$ Drugs prescribed were Glucosamine $(1500 \mathrm{mg} /$ day), Chondroitin sulphate (1000-1500mg/day), Diacerein (100mg/day) and MSM (Methyl Sulphonyl Methane) (1-3 gms/day) either alone or in combination along with NSAID's. Lifestyle modification included mainly reduction of obesity, quadriceps and hamstring muscle building exercises and avoiding extreme flexion at knee joint. Improvement in pain and functionality was recorded on WOMAC questionnaire sheet. Data was collected and statistically analyzed. (SPSS version 17.05)

\section{Aim of study}

The current study is aimed to find out the role of serum Cartilage Oligomeric Matrix Protein (COMP) levels for assessment of efficacy of on-going treatment in patients of knee osteoarthritis.

\section{Results}

There were 50 males and 50 females included in the study. The mean age was $59.93+9.20$ years and mean BMI was $24.07+3.1 \mathrm{~kg} / \mathrm{m}^{2}$. The difference in age and BMI of males and females was insignificant (p 0.001). The severity was determined by history taking, physical examination, WOMAC questionnaire and KL grade. There were 12 mild, 80 moderate and 8 severe osteoarthritis cases. According to grade of severity the cases were prescribed medications. The cases were monitored regularly and the improvement was recorded by WOMAC scoring and estimation of sCOMP levels.

The mean serum COMP values in mild cases group before the start of therapy it was $773.61 \mathrm{ng} / \mathrm{dl}$ and after therapy it declined to 654.7 $\mathrm{ng} / \mathrm{dl}$ showing an overall improvement of $15.37 \%$ (p 0.0003) (Table 1). In moderate severity group it was $1032.18 \mathrm{ng} / \mathrm{dl}$ before the therapy and it came down to $850.99 \mathrm{ng} / \mathrm{dl}$ after the therapy. The improvement was $17.55 \%(p<0.0001)$ (Table 2). Similarly in severe cases group it was $1241.67 \mathrm{ng} / \mathrm{dl}$ before the start of treatment and it decreased to $1067.67 \mathrm{ng} / \mathrm{dl}$, an improvement of $14.07 \%$ (p 0.0195) (Table 3).

\begin{tabular}{|c|c|c|c|c|c|c|}
\hline & Therapy & Case & $\begin{array}{l}\text { Mean Scomp } \\
\text { before Therapy }\end{array}$ & $\begin{array}{l}\text { Mean sCOMP } \\
\text { after Therapy }\end{array}$ & $\begin{array}{l}\text { Decrease in } \\
\text { Scomp Values }\end{array}$ & p-Value \\
\hline I & Lifestyle Modification & 02 & 767.86 & 721 & $6.10 \%$ & 0.0104 \\
\hline 2 & Glucosamine + Chondroitin Sulphate & $0 \mathrm{I}$ & 774 & 658 & $14.99 \%$ & 0.0001 \\
\hline 3 & Diacerein & 02 & 796.5 & 665.5 & $16.45 \%$ & 0.0019 \\
\hline 4 & $\begin{array}{l}\text { Lifestyle Modification }+ \text { Glucosamine + } \\
\text { Chondroitin Sulphate }\end{array}$ & 03 & 785.17 & 631.5 & $19.57 \%$ & 0.0001 \\
\hline 5 & Lifestyle Modification + Diacerein & 04 & 744.5 & 597.5 & $19.74 \%$ & $<0.0001$ \\
\hline 6 & Overall & 12 & 773.61 & 654.7 & $15.37 \%$ & 0.0003 \\
\hline
\end{tabular}


In mild cases the greatest improvement in serum COMP was obtained in group, treated with lifestyle modification along with diacerein whereas the least improvement was obtained in group treated with lifestyle modification alone (Table 1). In moderate cases the greatest improvement in serum COMP was obtained in group, treated with lifestyle modification along with glucosamine, diacerein and
MSM whereas the least improvement was obtained in group treated with lifestyle modification alone (Table 2). In severe cases the highest improvement in serum COMP was obtained in group, treated with glucosamine, diacerein and MSM whereas the least improvement was obtained in group treated with glucosamine and chondroitin sulphate (Table 3).

Table 2 Comparison of serum comp values before and after therapy in moderate cases

\begin{tabular}{|c|c|c|c|c|c|c|}
\hline & Therapy & case & $\begin{array}{l}\text { Mean sCOMP } \\
\text { before therapy }\end{array}$ & $\begin{array}{l}\text { Mean sCOMP } \\
\text { after therapy }\end{array}$ & $\begin{array}{l}\text { Decrease in } \\
\text { sCOMP values }\end{array}$ & p-value \\
\hline I & Lifestyle Modification & 17 & 1035.38 & 887.54 & $14.28 \%$ & $<0.0001$ \\
\hline 2 & Glucosamine + Chondroitin Sulphate & 15 & 1039.42 & 872.17 & $16.09 \%$ & $<0.0001$ \\
\hline 3 & Diacerein & 17 & 1013.75 & 845.67 & $16.58 \%$ & $<0.0001$ \\
\hline 4 & Diacerein + Glucosamine + msm & 18 & 1025.67 & 833.5 & $18.74 \%$ & $<0.0001$ \\
\hline 5 & $\begin{array}{l}\text { Lifestyle Modification + Diacerein, } \\
\text { Glucosamine + msm }\end{array}$ & 13 & 1046.67 & 816.08 & $22.03 \%$ & $<0.0001$ \\
\hline 6 & Overall & 80 & 1032.18 & 850.99 & $17.55 \%$ & $<0.0001$ \\
\hline
\end{tabular}

Table 3 Comparison of serum comp values before and after therapy in severe cases

\begin{tabular}{|c|c|c|c|c|c|c|}
\hline & Therapy & Cases & $\begin{array}{l}\text { Mean sCOMP } \\
\text { before Therapy }\end{array}$ & $\begin{array}{l}\text { Mean sCOMP } \\
\text { after therapy }\end{array}$ & $\begin{array}{l}\text { Decrease in } \\
\text { sCOMP values }\end{array}$ & p-value \\
\hline I & Glucosamine + chondroitin sulphate & 3 & 1163.5 & $100 \mid$ & $13.97 \%$ & 0.0404 \\
\hline 2 & Diacerein & 2 & 1309.5 & 1134 & $13.40 \%$ & 0.1506 \\
\hline 3 & Diacerein + glucosamine + msm & 3 & 1252 & 1068 & $14.70 \%$ & 0.1157 \\
\hline 4 & Overall & 8 & 1241.67 & 1067.67 & $14.01 \%$ & 0.0195 \\
\hline
\end{tabular}

\section{Discussion}

In clinical practice the diagnosis of osteoarthritis is normally based on clinical presentation and radiography. Usually no laboratory test is done to confirm or rule out the disease neither any test is done to ascertain and document the efficacy of on-going treatment, once it has been started. It is the patients subjective reporting only which guides a physician regarding the degree of success or failure of the on-going treatment. Since certain inflammatory arthritis, trauma to a joint and involvement of multiple joints especially hip and spine can also cause increased serum COMP values we excluded patients having evidence of hip and spine arthritis or inflammatory arthritis. Transient increase in serum COMP levels with exercise and its return to baseline levels within half hour of rest has been reported in literature. ${ }^{8}$ Diurnal variations in COMP levels have also been reported. ${ }^{3}$ Hence to avoid these confounding factors, subjects were made to rest for half an hour before drawing blood samples and the timing of drawing of blood samples was in afternoon.

The results in present study demonstrates a directly proportional relation between severity of knee osteoarthritis and serum COMP levels i.e. with increase in severity of knee osteoarthritis from mild to severe grade, higher values for serum COMP were obtained (Table 1-3). Our results are also supported by several authors who have pointed out about the relation between sCOMP with severity and prognosis of disease. , $^{4-12}$ Thus, these markers may have a role in assessing the disease severity and progression in Osteoarthritis patients. This study also favors the role of serum COMP in assessment of efficacy of treatment. We found that with on-going treatment, serum COMP value decreased in various treatment groups when compared to the pre therapeutic values. This decrease in serum COMP levels were favored by improved WOMAC score and other clinical parameters. In mild cases the highest improvement in serum COMP was obtained in group, treated with lifestyle modification along with diacerein whereas the least improvement was obtained in group treated with lifestyle modification alone. In moderate cases the highest improvement in serum COMP was obtained in group, treated with lifestyle modification along with glucosamine, diacerein and MSM whereas the least improvement was obtained in group treated with lifestyle modification alone. In severe cases the highest improvement in serum COMP was obtained in group, treated with glucosamine, diacerein and MSM whereas the least improvement was obtained in group treated with glucosamine and chondroitin sulphate.

The decrease in serum COMP value after different modalities of treatment has been reported by other authors as well. ${ }^{13-18}$ We did not come across any study where the change in SCOMP levels has been studied in different grades of severity with different treatment modalities and results compared. We, in our study, have compared the degree of improvement after treatment with various treatment modalities. The amounts of reduction in SCOMP values with different treatment modality have been statistically analyzed and significance reported. Hence in this study we suggest that serum COMP be used as a biomarker for assessment of efficacy of current treatment of knee osteoarthritis. Taking all these facts in consideration, a guideline for use and interpretation of result for serum COMP level in knee osteoarthritis should be framed, so that this can be used as an accurate and useful guide of severity, prognosis and efficacy of treatment in knee osteoarthritis. In some treatment subgroups the decline of serum COMP is less than those with other subgroups. 
This suggests that serum COMP can be used to assess the relative efficacy among various treatment modalities and thus in turn can give idea about best treatment for a given subject. In most of the cases, combination of pharmacotherapy along with lifestyle modification is a better management option than either pharmacotherapy or lifestyle modification alone. In most of the severe cases, lifestyle modification and pharmacotherapy have limited role and has only marginal decline in serum COMP levels. This suggests about consideration of surgical management in such patients. Hence, we can say that levels of serum Cartilage Oligomeric Matrix Protein can be used for assessment of severity and efficacy of treatment in knee osteoarthritis.

\section{Conclusion}

Since sCOMP levels tend to decline in most of the treatment subgroups, with on-going treatment hence serial values for serum COMP in a patient can give valuable information about efficacy of on-going treatment. This would in turn guide a physician when to modify or change his line of treatment. Since in this study the sample size is rather small, we suggest a multicentre study with a much larger sample size to be done.

\section{References}

1. Garnero P, Rousseau JC, Delmas PD. Molecular basis and clinical use of biochemical markers of bone, cartilage and Synovium in joint disease. Arthritis Rheum. 2000;43(5):953-968.

2. Patersson F, Boegarerd T, Svensson B, et al. Changes in cartilage and bone metabolism identified by serum markers in early osteoarthritis of the knee joint. Br J Rheumatol. 1988;37(1):46-50.

3. Andersson MLE, Petersson IF, Karlsson KE, et al. Diurnal variation in serum levels of cartilage oligomeric matrix protein in patients with knee osteoarthritis or rheumatoid arthritis. Ann Rheum Dis. 2006;65(11):1490 1494.

4. Hanan Darweesh, Doaa Abbass, Randa Kadah, et al. Serum and synovial cartilage oligomeric matrix protein (COMP) in patients with rheumatoid arthritis and osteoarthritis. Indian Journal of Rheumatology. 2010;5(3):112-117.

5. Singh S, Shahi U, Kumar D, et al. Serum Cartilage Oligomeric Matrix Protein: Tool for early diagnosis and grading of severity of primary knee osteoarthritis. International Journal of Osteology and Orthopedics. 2014;1(101):1-7.

6. Altman R, Asch D, Bloch G, et al. The American College of Rheumatology criteria for the classification and reporting of osteoarthritis of the knee. Arthritis Rheum. 1986;29(8):1039-1049.

7. Zhang W, Moskowitz RW, Nuki G, et al. OARSI recommendations for the management of hip and knee osteoarthritis, Part II: OARS evidence-based, expert consensus guidelines. Osteoarthritis Cartilage. 2008;16(2):137-162
8. Andersson ML, Thorstensson CA, Roos EM, et al. Serum levels of cartilage oligomeric matrix protein (COMP) increase temporarily after physical exercise in patients with knee osteoarthritis. BMC Musculoskelet Disord. 2006;7:98.

9. Sharif M, Saxne T, Shepstone L, et al. Relationship between serum cartilage oligomeric matrix protein levels and disease progression in osteoarthritis of the knee joint. Br J Rheumatol. 1995;34(4):306-310.

10. Bleasel JF, Poole AR, Heinegard D, et al. Changes in serum cartilage marker levels indicate altered cartilage metabolism in families with the osteoarthritis-related type II collagen gene COL2A1 mutation. Arthritis Rheum. 1999;42(1):39-45.

11. Vilim V, Vytasek R, Olejarova M, et al. Serum cartilage oligomeric matrix protein reflects the presence of clinically diagnosed synovitis in patients with knee osteoarthritis. Osteoarthritis Cartilage. 2001;9(7):612-618.

12. Sharif M, Kirwan JR, Elson CJ, et al. Suggestion of nonlinear or phasic progression of knee osteoarthritis based on measurements of serum cartilage oligomeric matrix protein levels over five years. Arthritis Rheum. 2004;50(8):2479-2488.

13. Crnkic M, Mansson B, Larsson L, et al. Serum cartilage oligomeric matrix protein (COMP) decreases in rheumatoid arthritis patients treated with infliximab or etanercept. Arthritis Res Ther. 2003;5(4):R181-185.

14. Forsblad d'elia H, Christgau S, Mattsson LA, et al. Hormone replacement therapy, calcium and vitamin D3 versus calcium and vitamin D3 alone decrease markers of cartilage and bone metabolism in rheumatoid arthritis: a randomized controlled trial [ISRCTN46523456]. Arthritis Res Ther. 2004;6(5):R457-468.

15. Weitoft T, Larsson A, Saxne T, et al. Changes of cartilage and bone markers after intra-articular glucocorticoid treatment with and without postinjection rest in patients with rheumatoid arthritis. Ann Rheum Dis. 2005;64(12):1750-1753.

16. Skoumal M, Haberhauer G, Feyertag J, et al. Serum levels of cartilage oligomeric matrix protein (COMP): a rapid decrease in patients with active rheumatoid arthritis undergoing intravenous steroid treatment. Rheumatol Int. 2006;26(11):1001-1004.

17. Mansson B, Carey D, Alini M, et al. Cartilage and bone metabolism in rheumatoid arthritis. Differences between rapid and slow progression of disease identified by serum markers of cartilage metabolism. J Clin Invest. 1995;95(3):1071-1077.

18. Wollheim FA, Eberhardt KB, JohnsonU, et al. HLA DRB1* typing and cartilage oligomeric matrix protein (COMP) as predictors of joint destruction in recent-onset rheumatoid arthritis. $\mathrm{Br} J$ Rheumatol. 1997;36(8):847-849. 